\title{
LAS MATEMÁTICAS EN SUS RELACIONES CON LA PROSPERIDAD DE LOS ESTADOS
}

José Cecilio del Valle

(1780-1834) 
El discurso Las matemáticas en sus relaciones con la prosperidad de los Estados fue pronunciado por delValle en la Ciudad de Guatemala el 16 de mayo de 1831 en ocasión de inaugurarse un curso de matemáticas. Este es sin duda uno de los escritos más importantes de este célebre sabio centroamericano. Es un escrito representativo del pensamiento ilustrado centroamericano que busca el progreso individual y social basado en la razón, bajo la convicción de que la humanidad se dirige a niveles desconocidos de progreso y perfeccionamiento a partir del conocimiento del hombre, la sociedad y la naturaleza. Todo esto por medio del desarrollo de las ciencias naturales, sociales y humanas en las cuales la matemática es fundamental.

Afirma Valle "No hay ciencias inútiles. Todas hacen bienes grandes al género humano. Pero las matemáticas son las que ayudan a producirlas". Este discurso trata precisamente del impacto de las matemáticas en todos los ámbitos de la vida. Entrenan al ser humano a pensar con exactitud, son la herramienta fundamental para conocer la naturaleza; desarrollar la ciencia de la riqueza; calcular los bienes y los males en las decisiones políticas; calcular el bien de los pueblos en materia de legislación; calcular la utilidad o el dolor en las decisiones morales; desarrollar las artes militares y evitar derramamientos de sangre innecesarios; asegurar la libertad de los pueblos.

Al desarrollo de las matemáticas también se les puede atribuir una influencia enorme para que la filosofia y las humanidades discurrieran con rigor. Este maravilloso escrito da lecciones sobre la importancia de las matemáticas en el desarrollo de los pueblos, más allá de las ciencias naturales donde estamos acostumbrados a pensar en su utilidad. Por ello constituye una estrategia de desarrollo muy vigente en la actualidad. 


\section{LAS MATEMÁTICAS EN SUS RELACIONES CON LA PROSPERIDAD DE LOS ESTADOS}

José Cecilio del Valle

$(1780-1834)$

El 16 de mayo de 1831 se abrió en Santo Domingo un curso de Matemáticas, por solicitud de la Junta Directiva de la Sociedad Económica. La concurrencia fué numerosa. Presidió el acto, el Director de aquella institución, quien pronunció el siguiente discurso:

\section{Ciudadanos:}

El establecimiento de cuatro clases donde se enseñen los elementos de las ciencias matemáticas, físicas, económicas y morales, ha sido desde hace mucho tiempo objeto constante de mis deseos.

Yo los manifesté a la Sociedad que trabaja modestamente en el verdadero bien del Estado: yo busqué profesor para la enseñanza de las primeras.

La Sociedad conoció su importancia y trascendencia; y un hombre benéfico que reúne las tres cualidades que debe poseer un maestro: el Deán de esta Santa Iglesia, que tiene ilustración, virtud y respetabilidad, ha ofrecido dar lecciones diarias de ellas. 
Se va a abrir la clase de matemáticas; y unas ciencias de tanto interés para la República, serán enseñadas a todos los que quieran aprenderlas.

El impulso dado al mundo arrastra a lo que se llama político. Pero cuando no se ha aprendido a calcular, ni se posee el arte de meditar con detenimiento, y discurrir con exactitud, es grande el peligro de equivocarse; y los errores en política son plagas que sacrifican generaciones, y hacen desaparecer pueblos enteros.

Las revoluciones comenzadas con objeto justo, se alejan a veces del término propuesto y marchan a extremos dolorosos. Es, hablando en general sin contraerme a ningún país en particular, porque creciendo la efervescencia llega al fin a enmudecer la razón: toman la palabra las pasiones: suceden las exaltaciones del entusiasmo, a los métodos severos del raciocinio: se habla como Dantón, y no se piensa como Newton. Si los directores de las revoluciones fueran estadistas acostumbrados a tener siempre el compás en la mano, y ejercitados en calcular las fuerzas y resistencias, las acciones y reacciones, los bienes y los males, la razón iría estableciendo su imperio sin derramar torrentes de sangre: la suerte de las naciones sería muy diversa, y para corregir un mal, no se harían sufrir muchos males.

Las matemáticas tienen una influencia muy alta. Ese compás, ese semicírculo, ese teodolito que parecen entretenimientos de la juventud, son instrumentos de grandes operaciones en lo político, en lo económico, en lo fisico y en todos aspectos.

Permítaseme contemplar las matemáticas en sus relaciones con la prosperidad de los Estados. Si lo político es lo que ocupa la atención, las matemáticas tienen aun en este sentido derechos muy grandes para reclamarla.

Los elementos del poder de un Estado, son la ilustración, la fuerza, la riqueza y la moralidad. Los salvajes que andan errantes por los bosques, son cuadro vivo de la desnudez y la miseria. Los pueblos inmorales abandonados a la corrupción, son víctimas de sus vicios. Las naciones ilustradas, ricas, fuertes y virtuosas, tienen los cetros del poder; y las matemáticas los ponen en sus manos. 


\section{ILUSTRACIÓN}

El hombre desvalido en la ignorancia, es poderoso en la ilustración. Las ciencias lo elevan del primero al segundo estado: las ciencias le dan el poder del pensamiento y el de la palabra; y estos poderes son, en la escala de la razón, los primeros del mundo.

Las ciencias del pensamiento, subiendo al origen obscuro de las ideas, y observando su formación y generaciones, enseñan a conocer los caracteres del error, y la divisa de la verdad: dan al hombre la fuerza del raciocinio; y con ella mueve masas que no podría levantar con otro poder.

Las de la palabra abrazan la inmensidad de los sonidos: los pulen y perfeccionan: los elevan a sistemas razonados de voces: forman los idiomas con que el hombre expresa sus sentimientos y necesidades; y poniendo en sus manos una nueva potencia, le dan la de convencer por la fuerza del discurso, o de encantar por las dulzuras de la armonía.

Las de la naturaleza corren los velos que la ocultan: levantan la corteza de los seres: descubren los tesoros del mundo y nos presentan el inventario de ellos.

Las de la riqueza contemplan la de los hombres y sociedades políticas: se elevan a su origen y siguen su desarrollo: fijan las leyes de su producción, distribución y consumo, y trabajan para que el hombre no esté desnudo, ni viva en las inmundicias de la miseria.

Las de la moral son, en aspecto más interesante, la guía de los individuos y pueblos. Enseñan virtudes y perfecciones: forman Sócrates y Arístides, Antonios y Marco Aurelios, y señalan la línea por donde deben caminar los hombres privados y públicos, las familias y las naciones, para no ser devoradas por la anarquía ni sacrificadas por el despotismo.

No hay ciencias inútiles. Todas hacen bienes muy grandes al género humano. Pero las matemáticas son las que ayudan a producirlas. Ellas enseñan a formar ideas exactas: ellas dan precisión, energía y fuerza al pensamiento. Desde el siglo feliz en que las matemáticas empezaron a hacer progresos, las ciencias ideológicas comenzaron también a tomar un carácter que no tenían antes de aquella época venturosa. Loke, Condillac, Desttut, de Tracy, 
son descendencia noble de los matemáticos que fueron acostumbrando a la perfección en todos los raciocinios y ciencias.

Del arte de pensar pasó la exactitud al de hablar y escribir. El uno es cuadro o imagen del otro, y ambos perfeccionados por las matemáticas, son las bases de la elocuencia y la poesía. El poeta que dictó los bellos versos sobre la virtud, moderación y naturaleza del hombre, es el mismo que escribió los elementos de la filosofia, Newton. En la elocuencia de D’Alembert se conoce, a la primera lectura, al geómetra inmortal de la Francia; y si los oradores y poetas deben pintar la naturaleza, las ciencias que la dan a conocer ¿no serán importantes para hacer sus cuadros?

La naturaleza sería un misterio impenetrable, si las matemáticas no derramaran luces sobre ella. El hombre, átomo de la tierra: átomo en el sistema de los mundos, no tenía esperanza de abrazarla en su inmensidad. El matemático enseñó a construir instrumentos de óptica, a calcular el tiempo, a medir los ángulos; y estas tres lecciones pusieron a los sabios en aptitud de penetrar lo que parecía imposible a sus alcances. Contaron los astros: midieron sus tamaños: determinaron sus figuras: calcularon sus movimientos: penetraron sus eclipses: manifestaron el sistema del universo. Copérnico, Galileo, Kepler, Newton, Laplace, estos hombres épocas en la historia de las ciencias, son los maestros de los físicos y naturalistas.

No es dado conocer la naturaleza sin las luces de las matemáticas; y de los senos de la naturaleza sale la riqueza, objeto interesante de la crisología o economía política.

Esta ciencia vagó al principio por sistemas errados, origen de sacrificios dolorosos en los pueblos inmolados por ellos. Vió después el método de las matemáticas mixtas que observan los hechos constantes y generales, y deducen de ellos las leyes o causas que los producen. Adoptó este método feliz, y desde entonces cesó de ser sistemática: se elevó a verdadera ciencia, o empezó a ser digna de ese título. Las matemáticas subieron a Smith al rango que le han señalado los sabios: las matemáticas dieron a Canard las formulas del álgebra: las matemáticas han puesto a Say y a Ricardo en estado de perfeccionar y enriquecer esta sección importante del saber humano. La economía política es una ciencia de observación y cálculo; y las naciones que 
han sabido observar y calcular mejor, son las que han hecho progresos más grandes. De la mayor cantidad posible de productos en el menor tiempo y en el menor trabajo posible, es el intento sublime de sus investigaciones y trabajos.Y este interesante objeto no podrá llenarse sin análisis y cálculos.

Los de las ciencias morales son más bastos y abrazan relaciones más complicadas. Si en todos los ramos de los conocimientos humanos, es importante discurrir con la exactitud y precisión con que acostumbran las matemáticas, en los políticos donde los resultados son más trascendentales, es sin duda mayor la necesidad. Los experimentos de un naturalista, los ensayos de un botánico, solo sacrifican la vida del animal que se diseca, o de la planta que se clasifica. Los de un estadista pueden matar millares de hombres, y hacer víctimas a centenares de pueblos. Todas sus operaciones son delicadas; en todas es precisa la observación, y necesario el cálculo. Si quiere tener a la vista el cuadro geográfico del Estado que debe conocer para saberlo gobernar, es preciso que las matemáticas enseñen a formarlo. Si quiere dictar una ley, es necesario que numere los bienes y los males que puede hacer, y compare los unos con los otros. Si quiere crear un sistema justo de hacienda, es indispensable que calcule la riqueza de la nación o individuos que la componen; y limitando los impuestos o las rentas, utilidades o ganancias, no toque jamás los capitales productores de ellas. Si quiere aprovechar las lecciones siempre importantes de la experiencia, debe hacer estudio profundo de las naciones; y la historia no puede atravesar los siglos, ni recorrer los pueblos, sin ser guiada por la cronología y geografía, secciones o partes de las matemáticas.

\section{RIQUEZA}

Poderoso con estas fuerzas el hombre pobre, por falta de conocimientos, llega por su instrucción a ser productor de riquezas.

La naturaleza forma las materias primeras en sus prodigiosos laboratorios. Pero la agricultura las extrae de sus senos: las artes y oficios les dan las formas que exigen nuestras necesidades: el comercio las transporta a los mercados; y todos estos agentes de producción necesitan de las matemáticas. 
La agricultura progresa en las labores de la tierra a proporción que avanza en las observaciones del cielo. Es uno el Todo inmenso que se llama universo. Todos los seres que lo forman están concatenados: todos se atraen: todos gravitan unos sobre otros. El movimiento de los planetas y sus satélites, lo produce en la atmósfera y el océano; y el de los aires y las aguas influye siempre en el cultivo. Si el curso de los primeros está sujeto a leyes invariables, el de los segundos debe estarlos igualmente. Y si puede predecirse el uno, podrá también pronosticarse el otro. A los fenómenos del cielo, siguen fenómenos proporcionales en la tierra. Hay verdadera correspondencia entre los primeros y los segundos; y penetrado de esta idea, un escritor eminente ${ }^{1}$ llegó a concebirla de elevar a la agricultura al grado de ciencia físico matemática. "Cuando se propague, dice, las fórmulas de corrección de las alturas, observadas por el barómetro, y se tenga un gran número de observaciones exactas, hechas en diferentes parajes y de modo que sean comparables, se podrán calcular las tempestades, las nevadas, las lluvias, los años secos, etc., etc., con mucha anticipación y la misma exactitud y precisión con que ahora se calculan los eclipses."

Llegará algún día esta época feliz. Mi alma ansiosa del bien, se inclina a creer lo que pueda hacerlo con tanta abundancia. Las matemáticas aplican a los progresos de las ciencias, todas las fuerzas del genio: los meteorologistas empiezan a ser infatigables en las investigaciones. Si la ley general del mundo, la gravitación, ha sido sometida al imperio de las matemáticas,

\footnotetext{
${ }^{1}$ El señor Doctor Mariano Vallejo autor del Tratado elemental de Matemáticas. Este sabio español que ha merecido tantos elogios a varias sociedades de Europa, leyó en el Jardín Botánico de Madrid el año de 1815, una disertación sobre el método de perfeccionar la agricultura por los conocimientos astronómicos y físicos, y elevarla al grado de ciencia físico matemática. Yo cito su nombre con gratitud. El año anterior me dirigió varios opúsculos sobre su nuevo método para enseñar a leer y escribir; y esos opúsculos han empezado a ser útiles a mi Patria. Los jóvenes de diversos países que iban a París a perfeccionar su educación, corrían peligros por su inexperiencia en aquella inmensa capital. El señor Vallejo, tiene en ella, casa de educación e instrucción, que los ha disminuido o hecho cesar.Y hubo este estímulo más para aprovechar la gracia del Excelentísimo señor Ministro de Marina, que había resuelto que todos los jóvenes de América que querían ir a Francia a perfeccionar su educación, gocen de libre pasaje en los buques del Estado.
} 
los fenómenos derivados de ella ¿no podrán también en el transcurso del tiempo estar sujetos a sus cálculos?

Las artes hermosean las bellezas formadas por la naturaleza, y extraídas por la agricultura. Un mundo nuevo más bello en los aspectos que el mundo antiguo, sale de sus talleres para utilidad y placer del hombre. Lo más bruto aparece animado: lo más inculto se presenta civilizado. Pero los brazos de las artes: las manos con que operan esta especie de creación, son los instrumentos y máquinas; y aquellos y éstas, son obras de las matemáticas. En Centro-América, donde no se cultivan las ciencias exactas, ni se estudia la mecánica, ni se conocen las máquinas e instrumentos que enriquecen a la Europa, la industria es casi nula; y lo será mientras no se vuelva a estos objetos toda la atención necesaria.

La de Inglaterra se ha elevado al grado más alto, porque la Inglaterra es país de los cálculos: la región de las matemáticas: el taller de los instrumentos y máquinas. Y la Francia empezó a hacer progresos asombrosos, desde que las ciencias comenzaron a ser aplicadas a las artes. El curso normal de la Geometría y Mecánica, de las artes y oficios, ha manifestado las relaciones que existen entre los talleres de los artesanos y los gabinetes de los sabios. Las matemáticas no son ya unas ciencias ocupadas exclusivamente en abstracciones. Dando diversas figuras a los maderos: aprovechando la fuerza del agua, del aire y del vapor: calculando las de los brutos, y colocándolos en diversas posiciones, aumentan los poderes del hombre, y hacen que sea el dueño o señor de la naturaleza, el que ha hecho de la Europa el ornamento más bello de la tierra, y hará de la América otro ornamento más grande y hermoso cuando a esta época de la juventud, volubilidad, exaltación y movimientos, suceda la de madurez, experiencia, fijeza y tranquilidad.

Solo en los tiempos de paz adelantan las artes ilustradas por los conocimientos de las matemáticas. Solo en los períodos de calma avanza el comercio guiado por las mismas.

El comercio interior es torpe, cuando no le auxilían las matemáticas; y el exterior no podría sin ellas dar un paso.

Las matemáticas presentan conocimientos para formar un sistema sabio de comunicaciones, necesario para la vida del comercio: ellas lo dan 
para hacer nivelaciones, abrir canales y construir caminos: ellas los ofrecen para que el hombre atraviese las zonas y recorra todos los climas.

No habría comercio sin navegación, ni sería posible surcar el océano sin la astronomía, ni elevarse al conocimiento de los cielos sin la óptica y la geometría. Las matemáticas guiaron a Colón en el descubrimiento de la América y presentaron al comercio un nuevo mundo: las matemáticas llevaron a Cook a la Australia, y presentando otra parte de la tierra han abierto otra plaza al comercio. Las matemáticas acaban de dirigir a Dumont d 'Urbille en su viaje al archipiélago inmenso de la Oceanía. Los viajes que hacen más honor al espíritu humano, se deben a las luces de las ciencias exactas; y si el comercio abraza la tierra entera en sus especulaciones, es porque las matemáticas, enseñando a conocer los astros, han enseñado a levantar cartas hidrográficas más exactas que las antiguas.

Todo sería aislamiento, pobreza y miseria en los tiempos de paz: todo sería, sangre, muerte y horror en los de la guerra, sino existieran las matemáticas.

\section{FUERZA}

En la América se ha derramado sangre a torrentes porque en la lucha de los partidos han peleado masas que, hablando en general, no han sido dirigidas por el genio de las matemáticas.

Estas ciencias áridas, abstractas, indiferentes, a primera vista, a los males del género humano, son eminentemente sensibles a todos los que sufre nuestra especie. Donde puede haber lágrimas, allí están las matemáticas meditando y calculando para disminuir su número.

Los ejércitos no son masas inorgánicas de hombres armados para atacar o defender. Son cuerpos mecánicos organizados por los principios de las ciencias exactas. Sus pasos, sus marchas, su reacción, sus movimientos, sus evoluciones: todo es medido o calculado.

Si las artes piden luces a las matemáticas, el de la guerra tiene una necesidad muy grande. La aritmética y el álgebra le dan lecciones de cálculo: la geometría le enseñanza a levantar planos: la geografía le da conocimientos 
del terreno: la mecánica se los ofrece sobre el choque de los cuerpos, sus movimientos y resistencias.

Reunir toda la fuerza necesaria en un tiempo y punto dados, es el problema difícil a que en último análisis redujo la ciencia militar, el hombre extraordinario de nuestro siglo; y este problema, el más delicado de todos, no pudo resolverse sin el auxilio de las matemáticas.

Sea que busque posiciones ofensivas o defensivas: que haga fosos o abra minas: que ponga sitio o que sea sitiado: que levante fortalezas o quiera destruir las levantadas: que ataque o defienda, el militar necesita los conocimientos de las matemáticas. Para ser digno de aquel título, es preciso hacer estudio profundo de ellas. Los que lo han hecho con más talento y método, son los que más se han distinguido en la historia de las naciones; y el que tiene en la del mundo lugar más eminente, debió a las matemáticas uno de los títulos más grandes de su gloria.

Si es necesario tener defensores, armados, de nuestros derechos, es preciso también comunicarles la ciencia que debe formar sus mentes y medir sus pasos. En todos los países cultos hay escuelas militares; y la base de ellas es el estudio de las matemáticas. Los sabios han demostrado su necesidad: los gobiernos han conocido sus relaciones con el arte de la guerra.

\section{MORALIDAD}

Las que tienen con las costumbres, son también obvias a quien se dedique a meditarlas. Sentir, pensar, discurrir, obrar, son actos sucesivos que tienen relaciones muy estrechas. El que aprende a pensar, aprende a obrar: el que sabe contar no sacrifica futuros largos a presentes breves: el que se en cálculos no se expone a sufrir años enteros de fuga, cárcel, hospital, pobreza y miseria, por gozar momentos de placer.

Uno de los matemáticos ${ }^{2}$ que hizo viaje al círculo polar para medir un grado del meridiano y terminar la disputa de cincuenta años, sobre la

\footnotetext{
${ }^{2}$ Mr. de Maupertuis, a quien las matemáticas y la fisica deben varias obras que han influido en sus progresos.
} 
figura de la tierra, escribió un Ensayo de filosofía moral, en que dió a esta ciencia el idioma y carácter de las exactas. Calculó los placeres y penas: enseñó a graduar su valor, y manifestó que la estimación de los momentos felices o infelices, es el producto de la intensidad del placer o pena, por su duración.

“Todo crimen es un falso cálculo del espíritu” dijo un orador ${ }^{3}$ coronado muchas veces por la Academia Francesa. Si hay pueblos que tienen la desgracia de ser inmorales, es porque las fuerzas que los impelen al vicio, son mayores que las que los alejan de él. No se les ilustra sobre sus verdaderos intereses: no se les enseña a calcular: no se trabaja para que vayan desde la infancia adquiriendo los hábitos felices de la virtud; y al mismo tiempo los placeres que promete el vicio, hacen sensación muy viva: los ejemplos de corrupción obran todos los días; y la ley que debía ser siempre reguladora sabia de sus acciones, es a veces extraviadora funesta de ellas.

Cuando el legislador no sabe calcular, es natural que el pueblo dirigido por él tenga ideas falsas, y marche por curvas que lo lleven al abismo.Ya se han manifestado los daños que hacen los legisladores que no saben sumar y restar bienes y males.

El jurisconsulto del siglo $^{4}$ ha hecho al género humano este gran presente. Su genio feliz ha elevado el análisis legislativo a un grado a que no lo había llevado ninguno de los sabios que le han precedido. Sus obras de

\footnotetext{
${ }^{3} \mathrm{Mr}$. Thomas en el discurso que pronunció el día de su recepción en la Academia Francesa.

${ }^{4}$ El señor Bentham, honor de la Inglaterra, donde nació, y de la especie humana de que es individuo. Cincuenta y cuatro años hace que comenzó a dar a luz y ha seguido publicando diversas obras para ilustración de los gobiernos y pueblos. Fracments of Government, fué la primera. Jeremy Bentham to his felow citizens of France, es la última. Publicó aquella el año de 1776, criticando varias opiniones Blakstone en sus comentarios. Dió a luz el año próximo del año 1830, después de los acaecimientos de París en los días memorables de Julio, contestando al General Lafayette que quiso saber su opinión sobre las Cámaras de París y Senados. Me la remitió en enero último: la recibí en el mes anterior, y en ella he admirado el análisis que distingue sus producciones. ¡Con qué placer las traduciría todas del inglés al castellano, si hubiera suscriptores bastantes para el costo de su impresión! La América ha comenzado a ser legisladora de sus hijos y le interesan especialmente las obras del Jurista que sabe analizar y pensar con exactitud: del talento que enseña a obrar con circunspección y detenimiento, en la ciencia más delicada por sus consecuencias y resultados: del genio que ha publicado un volumen intitulado "Aptitud de los funcionarios elevada al máximum. Gastos del Gobierno reducidos al mínimum.”
} 
jurisprudencia tienen el sello de las matemáticas; y las tablas que ha hecho, guiado por ellas, deben estar a la vista de los legisladores.

La influencia de las matemáticas es universal: se extiende a todos los elementos de prosperidad: abraza todas las clases de los Estados.

Convencida de esto la Sociedad hace los votos que inspira el verdadero patriotismo. Desea:

1. ${ }^{\circ}$ Que las luces de aquellas ciencias entren en los colegios de los que se dedican a las letras, en los talleres de los artesanos y en los almacenes de los comerciantes: en los campos del labrador y en los cuarteles del militar: en las masas de los pueblos y los salones de los Poderes.

2. ${ }^{\circ}$ Que el Gobierno se sirva con este objeto acordar las medidas más eficaces para propagar conocimientos tan útiles: que el estudio de las matemáticas sea una sección del plan general de los de la Universidad; y que entre tanto, se conceda a la clase que se abre en este día la protección que debe tener mientras exista:

3. ${ }^{\circ}$ Que los padres de familia envíen a ella sus hijos para que, acostumbrándose desde su primera edad a pensar con exactitud, sepan en las siguientes hacer su felicidad y la de su patria.

La desgracia de un individuo: la de una familia: la de un Estado, cuando no son producidas por algún acaecimiento o fenómeno de la naturaleza, tienen origen en algún error o cálculo falso. Hagamos esta observación y conoceremos todos los valores de la educación de la juventud.

Las ciencias dijo un matemático ${ }^{5}$ serán siempre señales de grandeza y felicidad de los pueblos; y la ignorancia será constantemente signo cierto de su miseria.

Abundan los elementos de riqueza en este hermoso Estado de Guatemala; y penetra de gozo la generosidad con que la naturaleza los ha derra-

\footnotetext{
${ }^{5}$ Mr. de Maupertuis en el discurso que dijo en su recepción de la Academia Francesa.
} 
mado por todas partes. Multipliquemos las manos que deben desarrollarlos: formemos hombres aptos para todos los oficios que hacen la prosperidad general. El Estado más floreciente es el que resume en sus hijos suma más grande de aptitudes. El Estado más feliz es el que tiene mayores capacidades.

Un individuo que no sabe pensar, leer, medir ni contar, es un ser dependiente de los que tienen estas aptitudes.Y una nación ignorante estará también en dependencia proporcional a su ignorancia.

La verdadera libertad exige ilustración: la educación da la ilustración que se necesita; y el estudio de las matemáticas es parte eminente de la educación. 